\title{
Experimental Investigation on the Effect of Rubber Powder on Mechanical Properties of PVA Fiber Concrete
}

\author{
Linling Ma, ${ }^{1}$ Bin Wang, ${ }^{2}$ Lei Zeng $\mathbb{D}^{1}{ }^{1}$ Yunfeng Xiao, ${ }^{1}$ Heng Zhang, ${ }^{1}$ and Zhen $\mathrm{Li}^{1}$ \\ ${ }^{1}$ School of Urban Construction, Yangtze University, Jingzhou, China \\ ${ }^{2}$ School of Civil and Architecture Engineering, Xi'an Technological University, Xi'an, China \\ Correspondence should be addressed to Lei Zeng; zenglei@yangtzeu.edu.cn
}

Received 6 November 2020; Revised 30 March 2021; Accepted 13 April 2021; Published 23 April 2021

Academic Editor: Peerapong Jitsangiam

Copyright (c) 2021 Linling Ma et al. This is an open access article distributed under the Creative Commons Attribution License, which permits unrestricted use, distribution, and reproduction in any medium, provided the original work is properly cited.

To verify the damping improvement by replacing partial sand with rubber powder in the concrete process, this study investigated the effects of the rubber powder $(5 \%, 10 \%, 15 \%$, and $20 \%)$ on the mechanical properties and micromechanism of polyvinyl alcohol (PVA) fiber-reinforced concrete. In addition, in order to discuss its damping performance, free vibration test was conducted. Microstructure analyses were conducted by the scanning electron microscope (SEM) test. These results indicated that, as the content of the rubber powder increased, the damping ratio increased, and the compressive strength decreased, but this strength loss can be effectively controlled by adding PVA fiber. The rubber powder with a volume content of $5 \%$ and PVA with a mass of $2.4 \mathrm{~kg} / \mathrm{m}^{3}$ were the most optimal mixing to balance the strength and damping requirement. According to the SEM test results, the rubber powder was beneficial to improve the damping ratio of PVA concrete, but it aggravated its interface defects.

\section{Introduction}

The vibration caused by earthquakes, wind, and other external excitations will lead to the damage or even failure of building structures. At present, vibration isolation and attached dampers are often used to control the vibration of structures in practical engineering [1-5]. However, these methods ignore the potential of building materials to improve their own damping and energy dissipation capabilities. Comparatively, the use of building materials with high damping performance can avoid the inconvenience and high cost caused by the installation of isolation and damping equipment, which has a better application value.

Polyvinyl alcohol (PVA) is a kind of synthetic fiber with acid and base resistance, high strength, high modulus, impact resistance, and good dispersion [6]. It has good dispersion in the cement matrix, high adhesion with cement, and obvious strengthening effect. Its application in concrete can significantly improve concrete impermeability, frost-thawing resistance, and impact resistance and reduce concrete brittleness. In addition, PVA fiber also has the characteristics of strain hardening and multicrack cracking $[7,8]$, which can significantly enhance the toughness and durability and reduce the shrinkage rate of concrete by more than $50 \%$. The existing literature shows that the application of PVA fiber in concrete has great potential and value. So far, the related research studies of PVA fiber concrete are mainly focused on the basic mechanical properties [7-11], bending behavior [12-14], impact properties $[11,15]$, mechanical properties under the freeze-thaw cycle [16-18], and high-temperature properties [19-23], while the damped energy dissipation characteristics concerned by engineering seismic research are less studied [24].

At present, China is the world's largest consumer of rubber, which correspondingly produces a large amount of waste rubber. The recycling of waste rubber is of great significance to the reduction of environmental pollution and the improvement of the human living environment. Some researchers have divided the discarded rubber tires into pieces and particles, added them into concrete, and then conducted compression tests and splitting tests on the concrete specimens [25-28]. The experimental results found that although compressive strength and bending strength of rubber concrete were reduced, its toughness improved 
[19, 29-31]. Additionally, researchers have also investigated the impact properties of rubber concrete [32-37]. The experimental results showed that rubber concrete has excellent impact toughness and high energy absorption capacity. As a viscoelastic material, rubber can be processed into powder and mixed into concrete to effectively enhance the damping performance of concrete and play a positive role in reducing the vibration of structures or components. However, the interface between the cement matrix and rubber powder is weak [38], which damages the strength of concrete. Therefore, the mixture of polyethylene fiber and rubber powder in concrete needs to have the right balance to meet the requirements of strength and damping properties.

In view of making full use of waste rubber and improving the energy dissipation capacity of concrete materials, this paper discusses the improvement on damping properties of PVA fiber-reinforced concrete through adding rubber powder. Material properties of composite concrete with PVA fiber and rubber powder are evaluated. A detailed experimental scheme is performed on the compressive strength, flexural strength, splitting tensile strength, damping, and dynamic stiffness of PVA fiber-reinforced concrete. The microstructure of rubber-reinforced PVA concrete was studied by SEM. Finally, the optimum substitution ratio in the scope of this experiment was obtained, which offered a reference for the application of PVA fiber concrete.

\section{Testing Program}

2.1. Materials. In this experiment, ordinary Portland cement with the strength grade of 42.5 was used as cementing material, and mixed water was taken from drinking-grade tap water. The coarse aggregate was artificial gravel with a particle size of no more than $20 \mathrm{~mm}$; the other property indices are shown in Table 1 . The natural river sand with a diameter of $2.3-3.0 \mathrm{~mm}$ was used as fine aggregate. The fiber was polyvinyl alcohol (PVA) fiber manufactured by Japan Kuraray Co., Ltd., and its properties are shown in Table 2. The rubber powder was produced and obtained by cutting waste tires, and the relative properties are shown in Table 3. In this experiment, rubber powder was added by equal volume instead of fine aggregate. SEM test was conducted to understand the surface morphology of the rubber powder (see Figure 1).

2.2. Mix Proportion Designs. The effect of different proportions of the rubber powder on the mechanical properties and microscopic mechanism was studied. In this experiment, a total of 6 groups of mixing ratios were designed, with 3 specimens for each group. The water-cement ratio (W/C) of all concrete is 0.4 , and the specific mix proportion is shown in Table 4 . The corresponding specimen numbers are listed as P0R0 to P1R20, where P represents the fiber and R represents the rubber powder. The rubber powder replacement ratio (rubber powder to fine aggregate in volume) is $5 \%, 10 \%, 15 \%$, and $20 \%$ (labelled with R5, R10, R15, and R20), respectively. The PVA fiber is added by a quantitative proportion of 0 and $2.4 \mathrm{~kg} / \mathrm{m}^{3}$ (labelled with P0 and P1). P0R0 is marked as the reference group with normal concrete. In addition, water reducer was provided by BASF Corporation, and the water reduction rate can reach $12 \%-20 \%$.

All mixtures were mixed with a forced concrete mixer. When adding fiber, in order to make fiber evenly distributed in concrete, the adding order was rubber powder, cement, then coarse and fine aggregates, and finally water and efficiency water reducer which were added for stirring. The composite concrete was then poured into plastic molds with four different sizes $(150 \mathrm{~mm} \times 150 \mathrm{~mm} \times 150 \mathrm{~mm}, 150 \mathrm{~mm} \times$ $150 \mathrm{~mm} \times 300 \mathrm{~mm}, \quad 100 \mathrm{~mm} \times 100 \mathrm{~mm} \times 400 \mathrm{~mm}$, and 80 $\mathrm{mm} \times 80 \mathrm{~mm} \times 1000 \mathrm{~mm}$ with reinforcement) and compacted for a short time on the vibration table. Finally, according to the Chinese code (GB/T50081-2002), the specimens were placed in a concrete-curing room $\left(20 \pm 2^{\circ} \mathrm{C}\right.$, $95 \%$ relative humidity $(\mathrm{RH})$ ) for 24 hours and continued to be cured for 28 days after demolding.

2.3. Static Material Properties' Test. The axial compression test, splitting tensile test, and flexural resistance test were carried out according to the Chinese code (GB/T500812002). The specimens' size was $150 \mathrm{~mm} \times 150 \mathrm{~mm} \times 300 \mathrm{~mm}$, $150 \mathrm{~mm} \times 150 \mathrm{~mm} \times 150 \mathrm{~mm}$, and $100 \mathrm{~mm} \times 100 \mathrm{~mm} \times 400$ $\mathrm{mm}$, respectively. The experiment was carried out with the $2000 \mathrm{kN}$ universal testing machine. The axial compression test was controlled by displacement loading with the loading speed of $0.5 \mathrm{~mm} / \mathrm{min}$, and the loading speed of the flexural and splitting tensile test was $0.05 \mathrm{MPa} / \mathrm{s}$.

2.4. Damping Properties' Test. The free vibration test of the reinforced concrete beams with the size of $80 \mathrm{~mm} \times 80 \mathrm{~mm} \times 1000 \mathrm{~mm}$ was carried out, and the damping ratio was measured $[33,34,38,39]$. The schematic diagram of the test device is shown in Figure 2, where the cantilever beam end length is $820 \mathrm{~mm}$. The arrangement of reinforcement in the beam is shown in Figure 3. Longitudinal ribs and stirrups with a diameter of $6 \mathrm{~mm}$ are arranged in the beam, the distance between the stirrups is $200 \mathrm{~mm}$, and the strength grade of the reinforcement is HPB235. The equipment and software used in the free vibration test were manufactured by Donghua Corporation, China, including INV018C signal acquisition analyzer, acceleration sensor, rubber hammer, and DASP analysis software. The experiment was carried out by changing the displacement of the cantilever end, and the displacement amplitude was $0 \mathrm{~mm}$, $5 \mathrm{~mm}, 10 \mathrm{~mm}, 20 \mathrm{~mm}, 30 \mathrm{~mm}$, and $40 \mathrm{~mm}$, respectively, which was expressed as $d_{0}-d_{5}$. The displacement loading procedure was as follows: the cantilever beam was first loaded by a jack to the determined displacement with the speed of $0.5 \mathrm{~mm} / \mathrm{min}$. Then, the cantilever beam was flipped $180^{\circ}$ and reloaded to the same determined displacement.

The test loading process is as follows: the rubber hammer is used to tap the middle part of cantilever beams, and the response signal of the specimen is collected through the acceleration transducer on the specimens. Then, the response signal is input into the computer through the signal acquisition system, and the damping ratio and natural 
TABLe 1: Property index of coarse aggregate.

\begin{tabular}{lccccc}
\hline Grain size distribution $(\mathrm{mm})$ & Apparent density $\left(\mathrm{kg} / \mathrm{m}^{3}\right)$ & Bibulous rate $(\%)$ & Silt content (\%) & Porosity (\%) & Crush indicators (\%) \\
\hline $5-20$ & 2730 & 0.60 & 0.34 & 44 & 9.0
\end{tabular}

TABle 2: Properties of the PVA fiber.

\begin{tabular}{lccccc}
\hline Density $\left(\mathrm{g} / \mathrm{cm}^{3}\right)$ & Diameter $(\mu \mathrm{m})$ & Length $(\mathrm{mm})$ & Tensile strength $(\mathrm{MPa})$ & Section expansion ratio $(\mathrm{cN} / \mathrm{dtex})$ & Elongation $(\%)$ \\
\hline 1.3 & 31 & 6 & 1600 & 320 & 6 \\
\hline
\end{tabular}

TABle 3: Properties of the rubber powder.

\begin{tabular}{lccc}
\hline $\begin{array}{l}\text { Particle size } \\
(\mathrm{mm})\end{array}$ & $\begin{array}{c}\text { Density }(\mathrm{kg} / \\
\left.\mathrm{m}^{3}\right)\end{array}$ & $\begin{array}{c}\text { Bibulous rate } \\
(\%)\end{array}$ & $\begin{array}{c}\text { Sieving rate } \\
(\%)\end{array}$ \\
\hline 0.178 & 1120 & $<10 \%$ & 95 \\
\hline
\end{tabular}

frequency are obtained. The free attenuation vibration in this initial state will be dominated by first-order vibration; through the spectrum analysis of the acceleration-time history, the basic frequency and the damping ratio of the first-order mode $\xi$ in the elastic stage and each damage stage can be obtained. The calculation formula of $\xi$ is shown in the following equation:

$$
\xi=\frac{1}{2 n \pi} \ln \frac{a_{i}}{a_{i+n}}
$$

where $n$ represents the number of decays, $A_{i}$ represents the $i$ th vibration amplitude, $A_{i+n}$ represents the $i+n$-th vibration amplitude, and $\xi$ represents the material damping ratio.

2.5. Scanning Electron Microscope Test. The microstructure of concrete describes its macroscopic properties, and the mechanism that affects its macroscopic properties can be understood through the study of the microcosmic interface. The micromorphology of the specimen was observed by using a field-emission scanning electron microscope (FESEM, MIRA3 TESCAN, Czech Republic). The samples were taken from prisms used in the axial compression test, with the diameter of $5 \mathrm{~mm}$ and the thickness of $2 \mathrm{~mm}$. It was noted that the samples should not contain coarse aggregate in order to observe the microscopic morphology of rubber particles and fibers in concrete. The samples were immediately moved into anhydrous ethanol to stop hydration, and ethanol was replaced every 24 hours. Before the experiment, the sample must be taken out and dried in the drying baker.

\section{Experimental Results and Discussion}

\subsection{Static Material Properties}

3.1.1. Compressive Strength and Stress-Strain Curve. The compressive strength of prisms after standard curing for 28 days is shown in Figure 4. The strength of fiber-reinforced concrete is $43.4 \mathrm{MPa}$. When $5 \%, 10 \%, 15 \%$, and $20 \%$ rubber powder were added, the strength of composite concrete decreased by $13.4 \%, 24.1 \%, 34.3 \%$, and $41.3 \%$, respectively. The reasons for the reduction of strength can be summarized as follows: (1) due to the low elastic modulus of rubber, it deforms greatly under the action of external forces. When the concrete specimen is compressed, the difference in deformation between rubber and aggregate will lead to the increase of tension at the rubber-cement interface. The cracking speed of the bonding interface is accelerated, which accelerates the development of internal cracks and leads to the destruction of the concrete specimen. (2) The hydrophobicity of rubber will weaken the adhesion between rubber powder and cement paste, and the increase of the rubber content will increase this interface defect, resulting in a sharp decline in the strength of concrete [40-43].

Figure 5 shows the axial compressive stress-strain curves of each specimen measured by the prism compression test. It could be seen that the stress-strain curve of PVA fiber concrete was basically consistent with that of reference concrete, but this trend changed when rubber was added. When the rubber content increased from $5 \%$ to $20 \%$, the rising stage of the curve gradually slowed down, the peak stress and strain decreased accordingly, and the slope of the descending section of the curve slowed down. During the loading process, PVA fiber could bear part of the tension, which relieved the stress concentration at the crack tip and prevented the occurrence and development of some microcracks. Moreover, rubber had the ability to withstand greater tensile stress, which could delay the expansion of cracks in cement slurry and avoid the complete disintegration of concrete. Therefore, although the strength of composite concrete was reduced, its toughness and ductility were improved.

3.1.2. Splitting Tensile Strength. The splitting tensile strength of cube specimens after standard curing for 28 days is shown in Figure 6. The splitting tensile strength of fiber-reinforced concrete is $2.24 \mathrm{MPa}$. When $5 \%, 10 \%$, $15 \%$, and $20 \%$ rubber powder were added, the strength of composite concrete, respectively, decreased by $28.5 \%$, $37.2 \%, 49.6 \%$, and $55.6 \%$. The combination surface of admixture and cement slurry affected the tensile capacity of concrete. Figure 7 (a) shows the splitting surface of the tensile specimen. Compared with the reference specimens, the composite concrete had more holes after adding fiber and rubber, which related to the decrease of tensile strength. As the total porosity of concrete increased, the initial net cross-sectional area decreased. When the concrete was acted on by external forces, the stress of each monomer in the concrete increased. In particular, when the proportion of large diameter pores was large, the area 

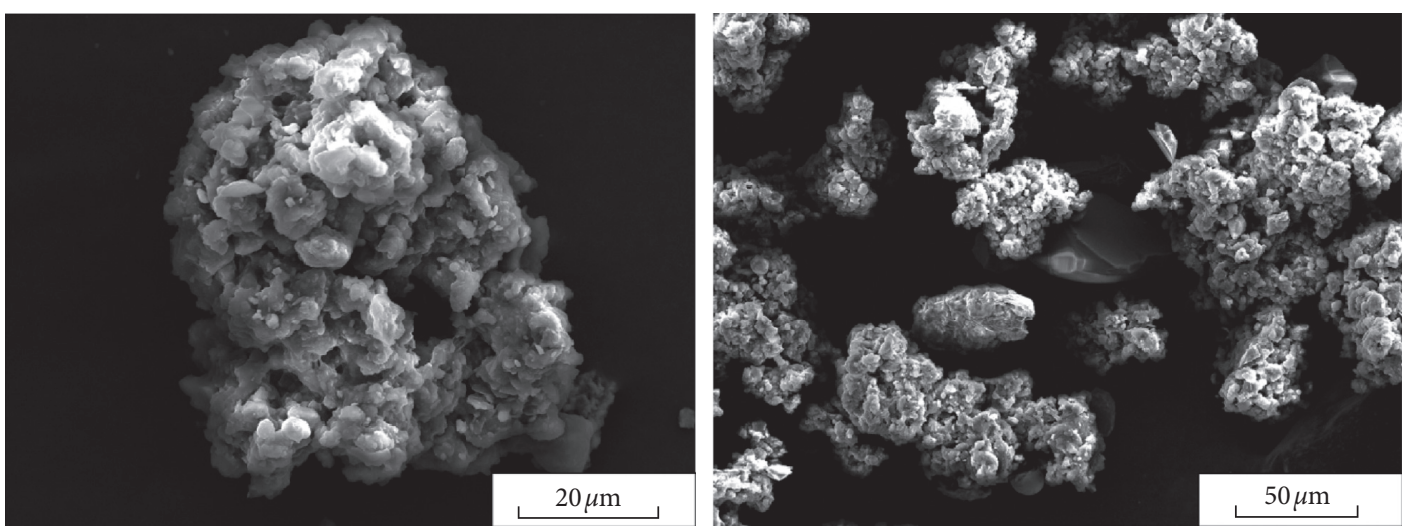

Figure 1: SEM of the rubber powder.

TABLE 4: Mix proportions of specimens.

\begin{tabular}{lccccccc}
\hline Numbers & $\begin{array}{c}\text { Water }(\mathrm{kg} / \\
\left.\mathrm{m}^{3}\right)\end{array}$ & $\begin{array}{c}\text { Cement } \\
\left.\mathrm{m}^{3}\right)\end{array}$ & $\begin{array}{c}\text { Coarse aggregate }(\mathrm{kg} / \\
\left.\mathrm{m}^{3}\right)\end{array}$ & $\begin{array}{c}\text { Fine aggregate }(\mathrm{kg} / \\
\left.\mathrm{m}^{3}\right)\end{array}$ & $\begin{array}{c}\text { Rubber }(\mathrm{kg} / \\
\left.\mathrm{m}^{3}\right)\end{array}$ & $\begin{array}{c}\text { PVA fiber }(\mathrm{kg} / \\
\left.\mathrm{m}^{3}\right)\end{array}$ & $\begin{array}{c}\text { HWR }(\mathrm{kg} / \\
\left.\mathrm{m}^{3}\right)\end{array}$ \\
\hline P0R0 & 185 & 463 & 1051 & 701 & 0 & 0 & 1.392 \\
P1R0 & 185 & 463 & 1051 & 701 & 666 & 17 & 2.4 \\
P1R5 & 185 & 463 & 1051 & 631 & 34 & 2.4 & 1.392 \\
P1R10 & 185 & 463 & 1051 & 596 & 51 & 2.4 & 1.392 \\
P1R15 & 185 & 463 & 1051 & 561 & 68 & 2.4 & 1.392 \\
P1R20 & 185 & 463 & 1051 & & & 0 & 1.392 \\
\hline
\end{tabular}

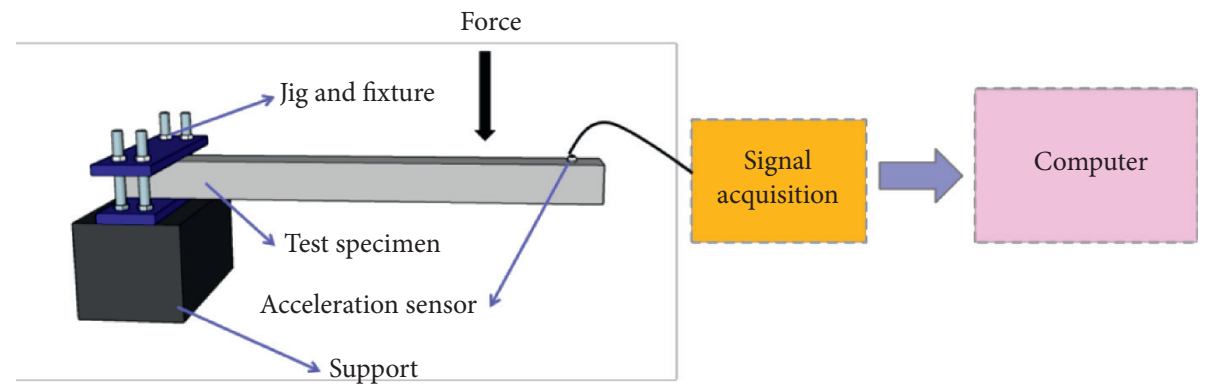

FIgURE 2: Damping ratio test device.
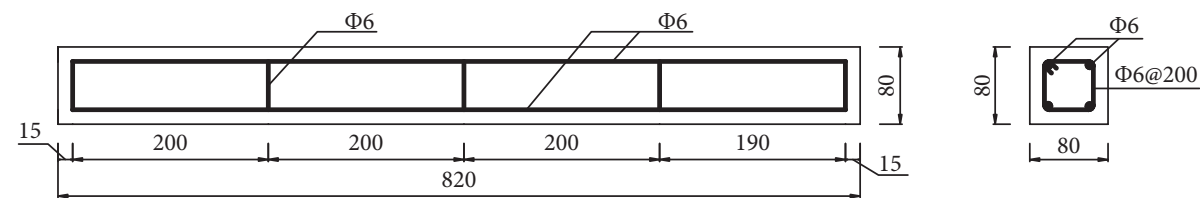

Figure 3: Schematic diagram of reinforcement distribution inside the cantilever beam.

of the net cross section decreased rapidly, and the failure load of the material decreased so that the strength of the material appeared to be very low. On the contrary, rubber in concrete did not participate in hydration and only played a simple physical filling role, which was difficult to form a complete consolidation with the cement slurry. The weak cementation surface increased the probability of tensile failure of the concrete interface under external forces.

One of the most important indicators to weigh the ductility of concrete is the tension-compression ratio (the ratio of splitting tensile strength to compressive strength).
Based on the test data in this experiment, the calculated tension-compression ratio of fiber concrete is 0.053 . After adding $5 \%, 10 \%, 15 \%$, and $20 \%$ rubber, the tension-compression ratio is $0.055,0.056,0.051$, and 0.050 , respectively. It can be seen that the influence of rubber on the tensioncompression ratio of fiber concrete is relatively small, generally showing a trend of first increasing and then decreasing. The continued increase of rubber not only fails to improve the ductility of composite concrete but may also have a negative effect. The reason is that the incorporation of rubber will cause uneven fiber distribution and weak interface effects of concrete. 


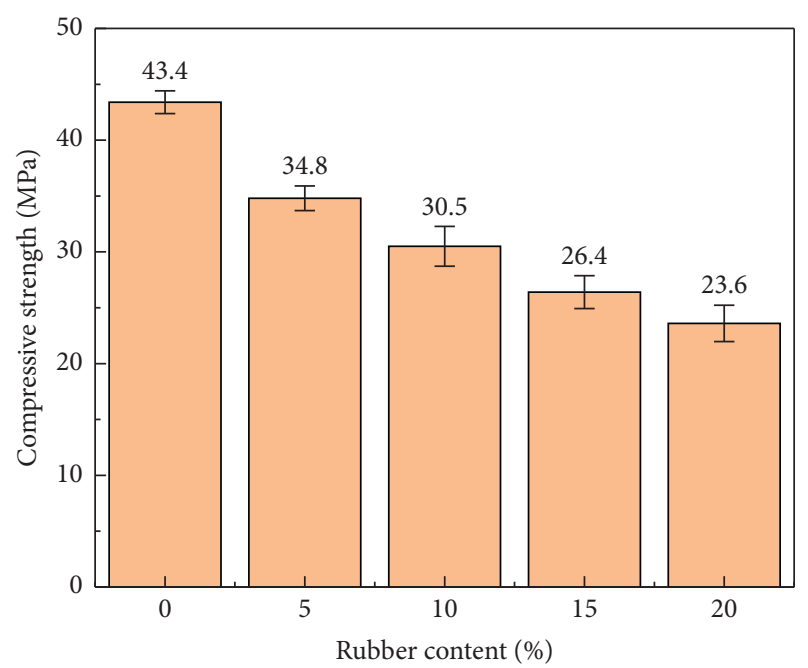

FIGURE 4: 28-day compressive strength of fiber concrete with different rubber contents.

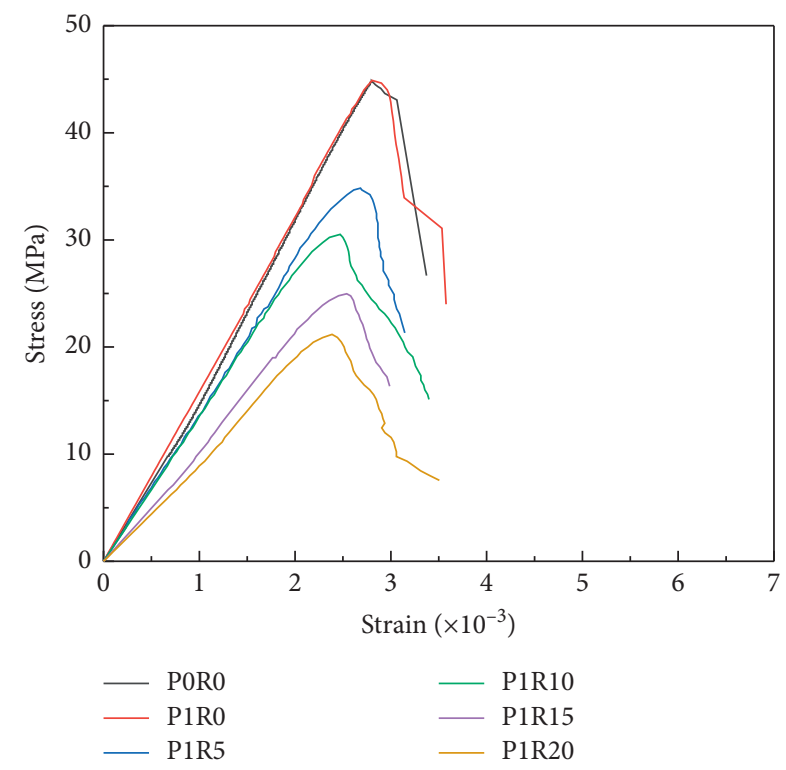

FIgURE 5: Axial compressive stress-strain curve.

In addition, fiber and rubber also affected the coarse aggregate in the splitting failure. As could be seen from Figure 7(b), the splitting surface of reference concrete showed obvious brittle failure, and the coarse aggregate was broken, but after adding fiber and rubber, the splitting surface showed the trace of the coarse aggregate falling off. When the concrete was under stress, aggregate and fiber would inhibit the crack, but the rubber powder filled at the interface between coarse aggregate and cement slurry would accelerate the crack expansion. It weakened the inhibiting effect of aggregate on crack development, led to premature separation of aggregate and cement slurry, and finally led to reduced strength.

3.1.3. Flexural Strength. Figure 8 shows the flexural strength of composite concrete with diverse rubber content. The experimental results showed that the flexural strength of

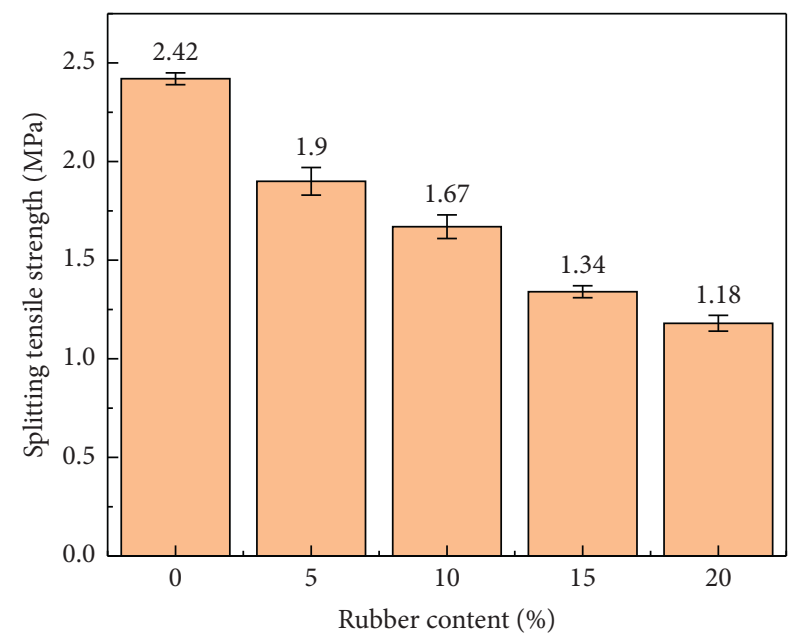

FIGURE 6: 28-day splitting tensile strength of fiber concrete with different rubber powders.

concrete was reduced after adding fiber, and rubber powder aggravated strength loss. Compared with reference concrete, the flexural strength of composite concrete decreased by $28.1 \%, 34.5 \%, 37.8 \%$, and $43.6 \%$, respectively, while that of fiber concrete decreased by $26.0 \%, 32.6 \%, 36.1 \%$, and $42.1 \%$, respectively. The essence of the flexural test was the tensile of the internal concrete, so the cause of bending strength and tensile strength loss of composite concrete made of PVA fiber and rubber was the same. The main reasons for the decrease of flexural strength were uneven fiber dispersion and weak adhesive force between rubber powder and cement slurry.

One of the most important indexes reflecting the toughness of concrete is the compression ratio (the ratio of flexural strength to compressive strength). Calculating from the above experimental data, the compression ratio of fiber concrete is 0.112 . After adding $5 \%, 10 \%, 15 \%$, and $20 \%$ rubber, the compression ratio is $0.104,0.108,0.118$, and 0.120 , respectively. When the fiber content is $2.4 \mathrm{~kg} / \mathrm{m} 3$, the continued increase of rubber will increase the compression ratio of the composite concrete and improve the toughness of the composite concrete.

\subsection{Damping Properties}

3.2.1. Damping Ratio and Basic Frequency. Figure 9 indicates the acceleration-time curve of the concrete beam obtained by the free vibration test. The damping ratio is calculated by equation (1). Tables 5 and 6 , respectively, show the damping ratio and basic frequency of each specimen under different damage levels. According to Figure 10, the damping ratio of PVA fiber concrete increased with the increase of the mixing amount of the rubber powder, but the increase amplitude decreases with the growing of rubber content with the increase of the mixing amount. When 5\% rubber was added, the damping ratio of the composite concrete reached the maximum value, and the damping ratio increased to $3.83 \%$, which was $84.1 \%$ higher than that of single fiber concrete. After the rubber content increased to 

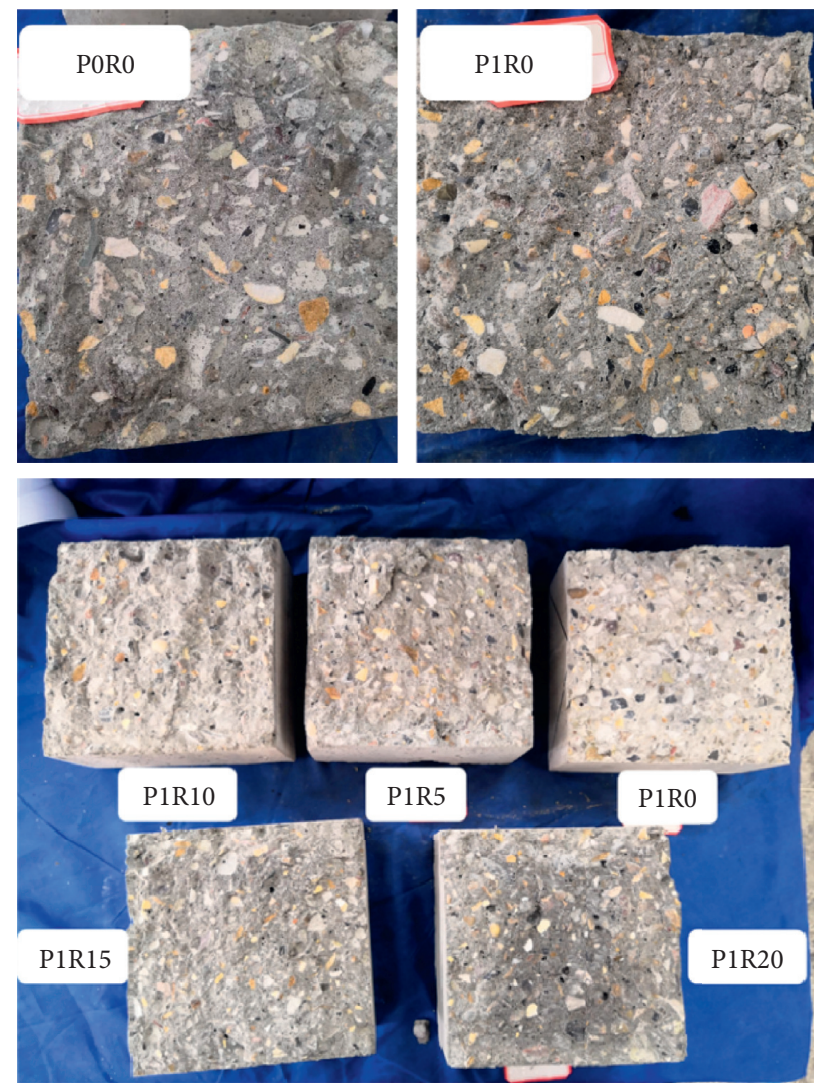

(a)
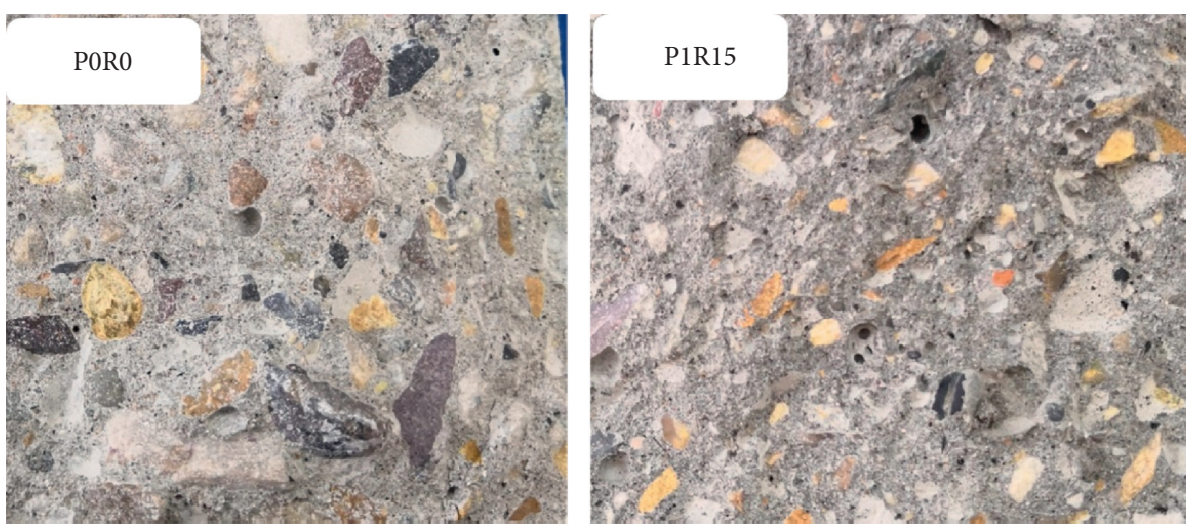

(b)

Figure 7: The fracture surface in concrete.

$10 \%-15 \%$, the damping ratio was about $2.91 \%$. When the content reached $20 \%$, the damping ratio was $2.36 \%$. The reason why rubber increases the damping ratio is that the rubber powder is distributed in concrete as the hyperelastic material. When rubber is subjected to external vibration, rubber consumes energy through its large deformation. The more rubber is added into the concrete, the more the elastic elements will be introduced into the concrete, and the final performance is the improvement of the concrete damping performance. Although the damping ratio is improved obviously by adding rubber, the addition of rubber affects the uniform distribution of the fiber and reduces the amount of cement slurry coated on the fiber surface. Therefore, as the rubber content increases, this lifting effect for damping ratio decreases.

With the increase of the damage stage, the basic frequency of the cantilever beam decreased gradually. When the control displacement was $20 \mathrm{~mm}$, the damping ratio of the cantilever beam reached the maximum value, which was about 3 times at the nondestructive state. The increasing degree of damage destroyed the integrity of the beam and caused quality loss. In this process, both the number and length of cracks in the cantilever beam increased, which increased the total surface area of the cracks. The energy 


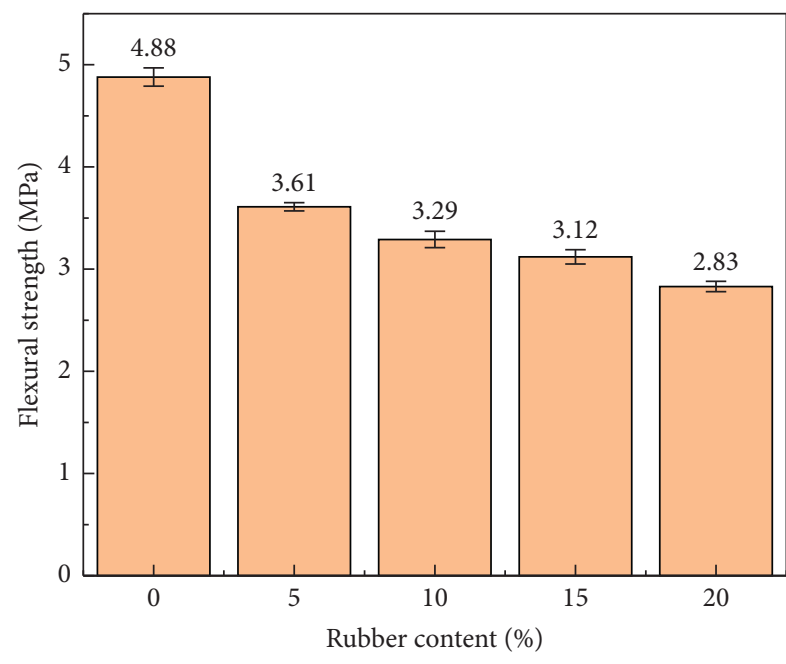

Figure 8: 28-day flexural strength of fiber concrete with different rubber contents.

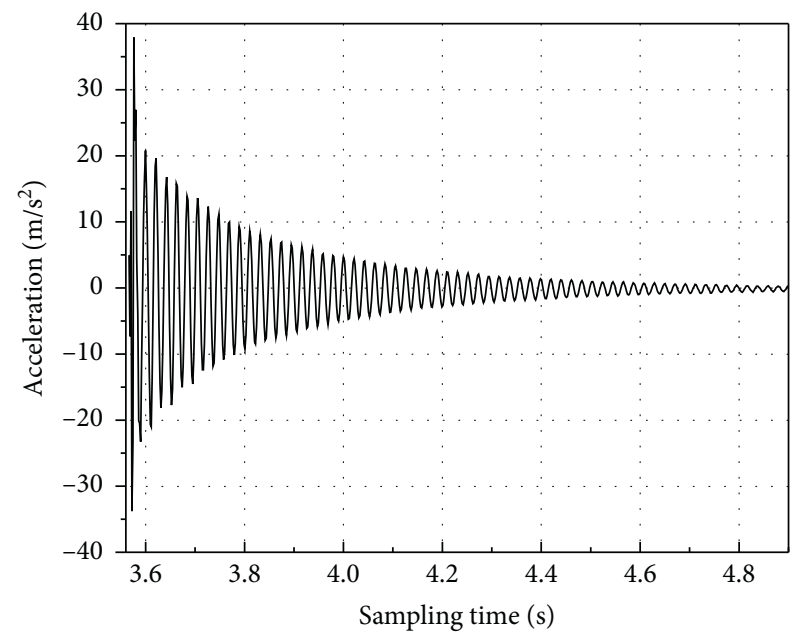

FIGURE 9: Acceleration-time curve of the concrete beam.

TABLE 5: Damping ratio of the concrete beam at each damage stage.

\begin{tabular}{lllllll}
\hline$d_{i}(\mathrm{~mm})$ & P0R0 & P1R0 & P1R5 & P1R10 & P1R15 & P1R20 \\
\hline 0 & $1.76 \%$ & $2.08 \%$ & $3.83 \%$ & $3.09 \%$ & $2.72 \%$ & $2.36 \%$ \\
5 & $4.12 \%$ & $3.04 \%$ & $5.31 \%$ & $3.63 \%$ & $4.18 \%$ & $3.39 \%$ \\
10 & $6.36 \%$ & $4.97 \%$ & $6.69 \%$ & $5.47 \%$ & $4.93 \%$ & $4.72 \%$ \\
20 & $4.43 \%$ & $5.38 \%$ & $7.82 \%$ & $6.13 \%$ & $6.48 \%$ & $5.91 \%$ \\
30 & $4.23 \%$ & $6.86 \%$ & $6.54 \%$ & $5.56 \%$ & $5.17 \%$ & $6.82 \%$ \\
40 & $3.89 \%$ & $5.72 \%$ & $6.02 \%$ & $5.08 \%$ & $4.78 \%$ & $6.43 \%$ \\
\hline
\end{tabular}

TABLE 6: Basic frequency of the concrete beam at each damage stage (unit: $\mathrm{Hz}$ ).

\begin{tabular}{lcccccc}
\hline$d_{i}(\mathrm{~mm})$ & P0R0 & P1R0 & P1R5 & P1R10 & P1R15 & P1R20 \\
\hline 0 & 53 & 47.5 & 52 & 47.5 & 47.5 & 43 \\
5 & 40.5 & 45 & 34.5 & 45.75 & 38 & 41.5 \\
10 & 36.5 & 33 & 28 & 36 & 33 & 31 \\
20 & 33 & 29 & 26 & 32 & 31.5 & 29.5 \\
30 & 31 & 28.5 & 25.5 & 31.5 & 31 & 25.5 \\
40 & 29.5 & 22.5 & 22 & 28.5 & 29 & 23 \\
\hline
\end{tabular}

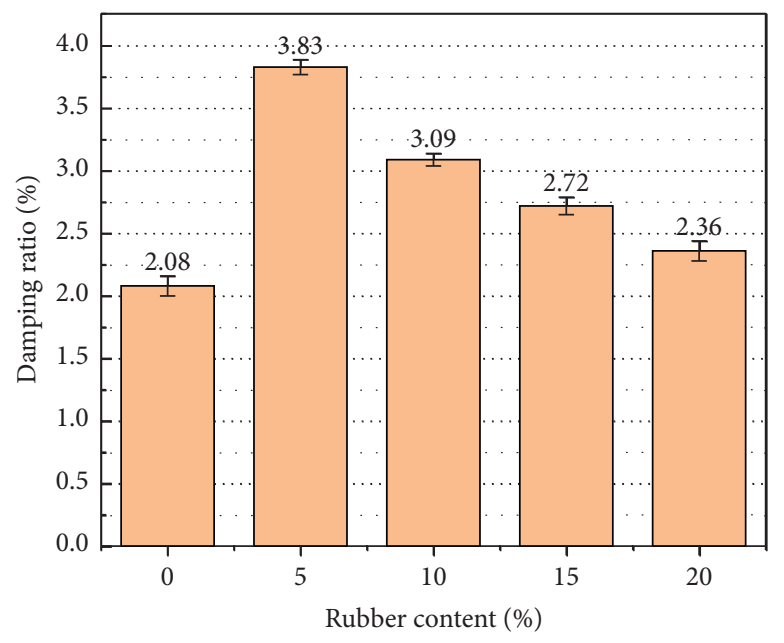

FIgURE 10: Damping ratio of fiber concrete with different rubber powder contents.

dissipated through friction between the cracks, thus increasing the damping ratio. After the number of cracks was stable, when the crack development length reached the maximum and the crack could be closed after unloading, the fracture interface area was the largest, the interface friction force was the strongest, and the damping ratio reached the maximum. After the crack penetration, with the aggravation of the damage stage, the crack develops from partially closed to nonclosed after unloading. In this process, mass loss gradually appeared at the beam root, and interface friction gradually decreased. In addition, the frictional strength decreased with the decrease of vibration frequency, so the damping ratio began to decrease.

3.2.2. Dynamic Bending Stiffness. Considering the small mass loss, a simplified method is used to calculate the bending stiffness of the beam at various loading levels. No mass loss is assumed in the calculation. According to the structural dynamics theory [44], the calculation formula of $\mathrm{EI}_{d 0}$ can be obtained (see equation (2)).

$$
\mathrm{EI} d 0=\frac{\left(2 \pi f_{0}\right)^{2}}{12.36} m l^{4},
$$

where $m$ and $l$ are the linear mass and length of the cantilever beam, respectively, and $f_{0}$ is the basic frequency of the cantilever beam in the elastic stage.

Then, the normalized bending dynamic stiffness at each displacement level can be expressed as follows [39]:

$$
\mathrm{EI}_{d i}^{*}=\mathrm{EI}_{d i} / \mathrm{EI}_{d 0}=f_{i}^{2} / f_{0}^{2} .
$$

Figure 11 shows the influence of control displacement $d_{i}$ on the dynamic stiffness of beam bending. In Figure 11, the trend of the stiffness degradation curve of curve P0R0 and curve P1R0 was similar. $\mathrm{EI}_{d i}^{*}$ decreased with the increase of the control displacement, especially when the control displacement was less than $20 \mathrm{~mm}$, it decreased rapidly. When the control displacement increased from $20 \mathrm{~mm}$ to $40 \mathrm{~mm}$, the decline range of $\mathrm{EI}_{d i}^{*}$ decreased. However, the dynamic 


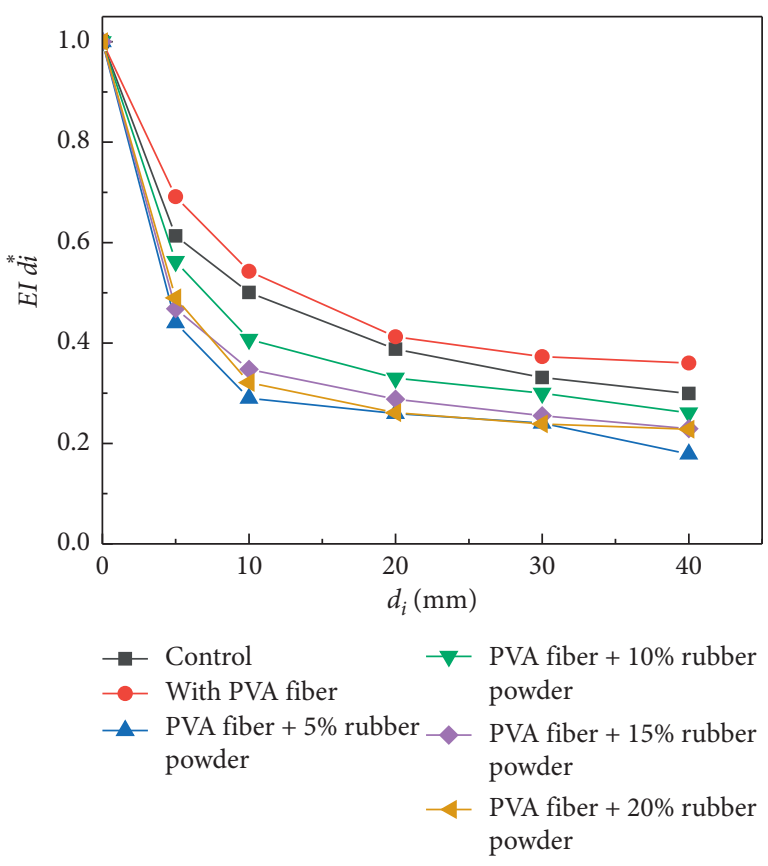

FIGURE 11: Relationship between dynamic stiffness of section bending and control displacement.

stiffness of curve P1R0 was relatively low compared with that of curve P0R0. By comparing EI ${ }_{d i}^{*}$ of specimens P0R0 and P1R0 under the same displacement value, the dynamic stiffness of the P1R0 specimen increased by about $12.1 \%$. When the reinforced concrete member was stressed, the internal fiber could consume part of the external force, so the fiber inhibited the stiffness degradation of the member to some extent.

Compared with the stiffness curve of POR0, the dynamic stiffness degradation rate of each curve (P1R5, P1R10, P1R15, and P1R20) increased significantly after adding rubber to fiber concrete. In addition, the sample after adding rubber decreased faster in the early stage of loading, and when $d_{i}=10 \mathrm{~mm}, \mathrm{EI}_{d i}^{*}$ decreased by about $71 \%$. The increase of the rubber content led to an increase in the internal pores and accelerated the stiffness degradation of concrete components.

3.2.3. Damage Index and Displacement Angle. Under the repeated action of external forces, the damage of reinforced concrete members will gradually accumulate and increase; because its damage stage is related to displacement amplitude, accumulated energy consumption, working stress amplitude, and other factors, scholars put forward the damage index to quantitatively describe the damage stage. The modes, periods, and dampers of RC members change at different damage stages, so the damage stage of members is described quantitatively according to the basic periodic changes. According to the reference, the damage index DI can be calculated by the following equation [45]:

$$
\mathrm{DI}=1-\left(\frac{T_{0}}{T_{i}}\right)^{2}=1-\left(\frac{f_{i}}{f_{0}}\right)^{2},
$$

where $T_{0}$ is the basic period of the initial elastic phase of the concrete structural members and $T_{i}$ is the basic period of the damage displacement of the $i$ phase.

The relationship between DI of the cantilever beam damage index and displacement angle $\theta_{i}=d_{i} / l$ is shown in Figure 12. As the displacement angle increased, the damage index of the cantilever increased, and before displacement angle $\theta_{i}$ was less than 0.025 , DI increased rapidly and then slowed down. The damage index growth rule of specimen P1R0 was close to that of specimen P0R0, but the damage index of P1R0 was smaller than that of P0R0. It showed that the damage index after adding PVA fiber decreased in growth rate and degree compared with that of reference concrete.

The damage index of the four groups of curves (P1R5, P1R10, P1R15, and P1R20) after adding the rubber powder had the same rule. Compared with the curve of P0R0, the damage index was larger, and its growth rate and degree increased significantly. When $i$ was 0.012 , the damage index increased from 0.49 to 0.71 . The addition of rubber obviously accelerated the destruction of reinforced concrete members. Through the analysis of the above damage index, DI and $\theta_{i}$ of the cantilever beam were fitted. The fitting result is shown in Figure 13, equation (5) is the fitting formula, and its correlation coefficient is 0.83 .

$$
\mathrm{DI}=0.14+42.3 \theta_{i}-641.9 \theta_{i}^{2} .
$$

\subsection{Relationship of Mechanical Strength and Damping Ratio of} Concrete. To understand the relationship between strength parameters and damping ratio, the axial compressive strength, flexural strength, splitting tensile strength, and damping ratio were treated as dimensionless. The relative ratio of each specimen to the reference specimen is defined as $R$, as shown in the following equation:

$$
R_{i j}=C_{i j} / B
$$

where $C_{i j}$ represents the parameter value of the specimen in which the rubber powder content is $i$ and the fiber content is $j$ and $B$ represents the parameter value of the reference group.

The relation between relative damping ratio and relative mechanical strength is shown in Figure 13. The comparison results showed that the increase of the relative damping ratio was accompanied by the decrease of their mechanical strength. When the content of rubber was $5 \%$, rubber had the greatest damping effect on fiber concrete, and the strength reduction was within $30 \%$. When the rubber content exceeded 5\%, the rubber-enhanced damping effect was reduced, but it was still higher than the reference concrete. The damping properties of concrete were affected by many factors, such as water-cement ratio, fiber length, rubber particle size, concrete mixing time, and curing conditions. Therefore, the damping properties of concrete were discrete, and it was difficult to express the relationship between the mechanical parameters and the damping ratio accurately. The high-damping and high-strength concrete 


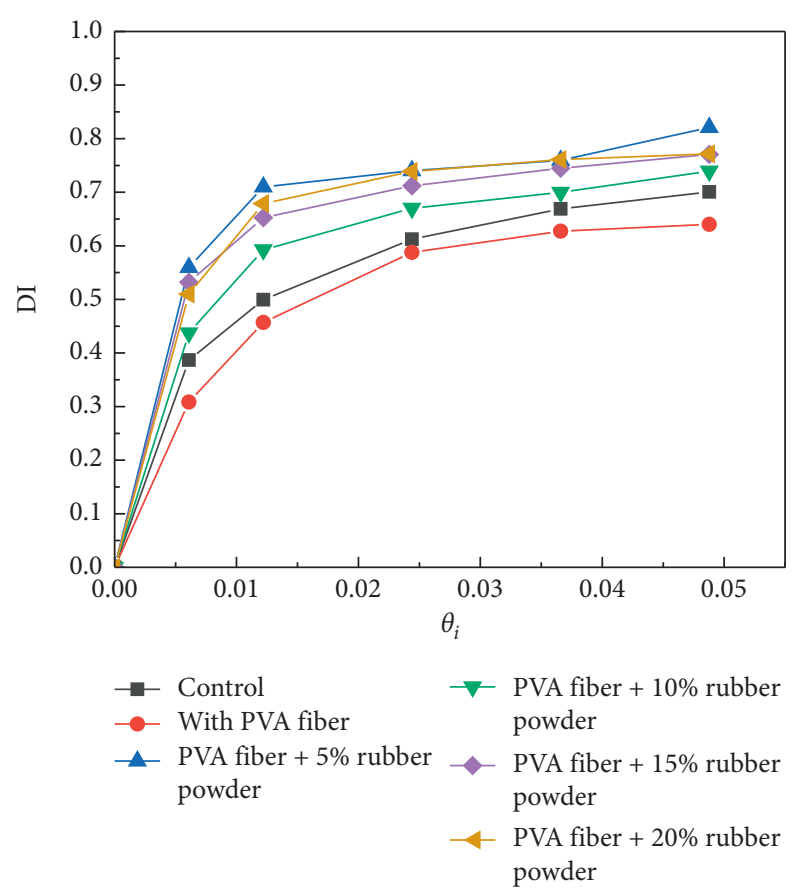

FIGURE 12: Relationship between damage index and displacement angle.

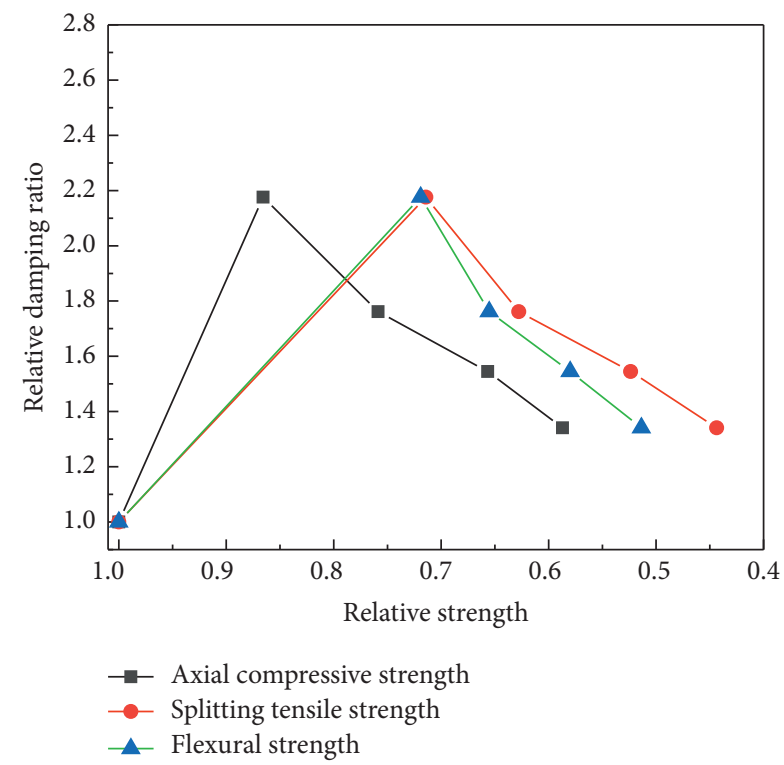

FIGURE 13: Relationship between relative damping ratio and various mechanical parameters.

can be obtained by improving the mixing technology, fiber type, and dispersing technology of concrete.

3.4. SEM Test Results. The interfacial relationship between the internal components of the concrete has an important influence on the performance of the concrete. Based on the SEM test, the distribution of rubber and PVA fibers added to the concrete and the adhesion of the interface with the cement slurry were known. Figure 14 refers to the microscopic images

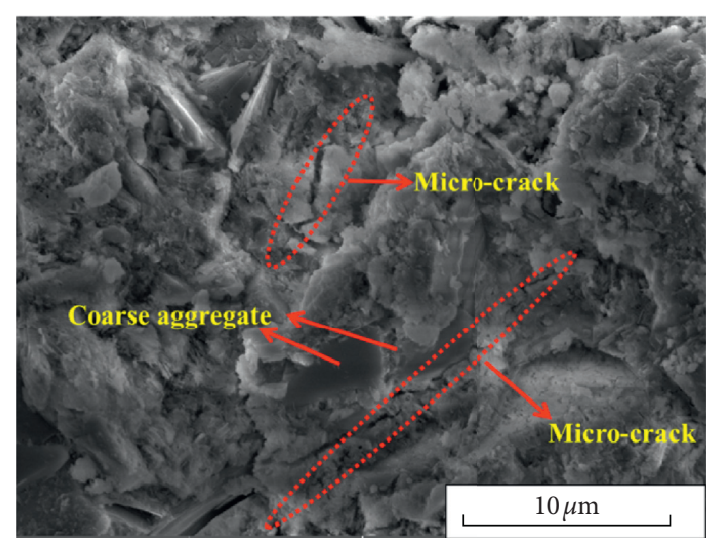

FIGURE 14: Surface topography of the reference concrete.

of concrete samples, from which it can be observed that the microcrack exists on the concrete surface. These cracks came from shrinkage cracks caused by concrete shrinkage and microcracks caused by water bleeding around the aggregate, and they usually existed before the concrete was stressed. After adding PVA fibers, PVA fibers were randomly distributed in the three-dimensional state of the concrete, which changed the propagation path of the cracks and optimized the micropore structure inside the concrete. Figure 15 shows the microscopic image of the PVA fiber in concrete, in which a lot of C-S-H gel is attached to the surface and surrounding of the PVA fiber, reflecting the good adhesion between PVA fiber and cement slurry.

Figures 16 and 17 are microscopic images of the rubber powder in concrete. In Figure 16, the glue powder was not tightly bound to the cement slurry, which might be due to the insufficient cement slurry penetration between the two during the pouring process of the specimen. To further understand the microscopic interface of rubber in concrete, the adhesive part between cement and rubber powder in Figure 16 was further enlarged. As can be seen from Figure 17, rubber itself also had gaps, which reduced the contact area between rubber powder and cement slurry and aggravated the interface defects of concrete. Under the action of concrete load, interface defects would accelerate the extension and the formation of through cracks, eventually leading to the decline of concrete mechanical properties. However, these gaps gave rubber enough space to contract when it vibrated, which had a positive effect on the damping performance.

Figures 18 and 19, respectively, show the microimages of the concrete surface before and after adding PVA fiber and rubber powder. The comparison of the two figures shows that the number of holes and the diameter in Figure 19 increase. The distribution of internal fibers was not uniform, and some fibers were not dispersed. Therefore, it could be concluded that these holes, on the one hand, were caused by the fall off of aggregates and rubber powder. On the other hand, due to the fibers cohered to fibers and scattered randomly in concrete, the flow of concrete was blocked, and pores were formed. In addition, there were more round bubble-like holes on the concrete surface in Figure 19. The air produced during mixing in concrete was 


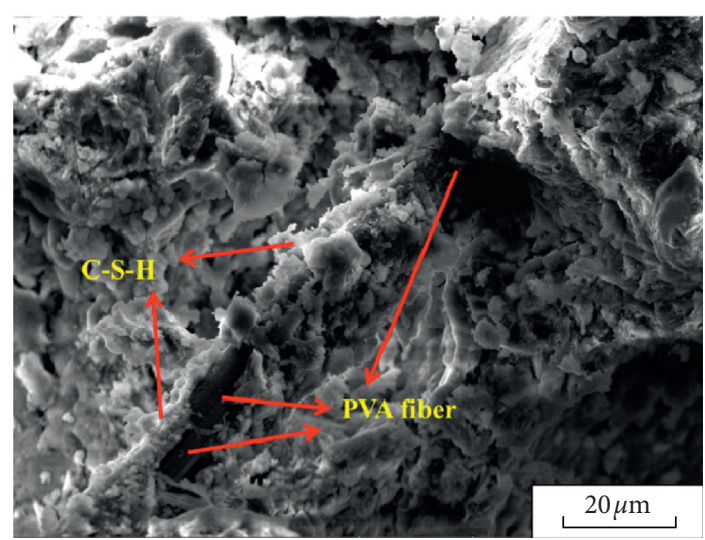

FIGURE 15: Microstructure of the PVA fiber in concrete.

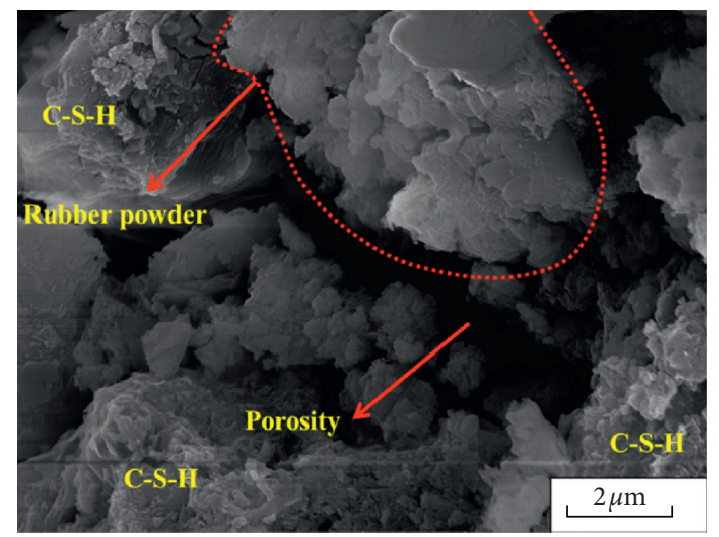

FIGURE 16: Interface between rubber powder and cement slurry.

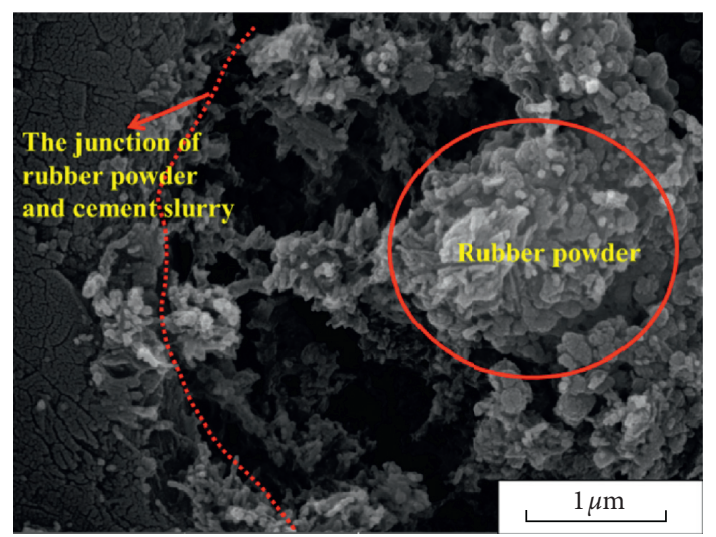

FIGURE 17: The internal microstructure of the rubber powder.

blocked by randomly distributed fibers. It was hard for the air to escape, and it ended up in the concrete and formed these holes. The presence of these pores reduced the strength of fiber concrete, yet when concrete materials were subjected to external vibration, they dissipated energy as the flexible buffer packages to increase the damping performance.

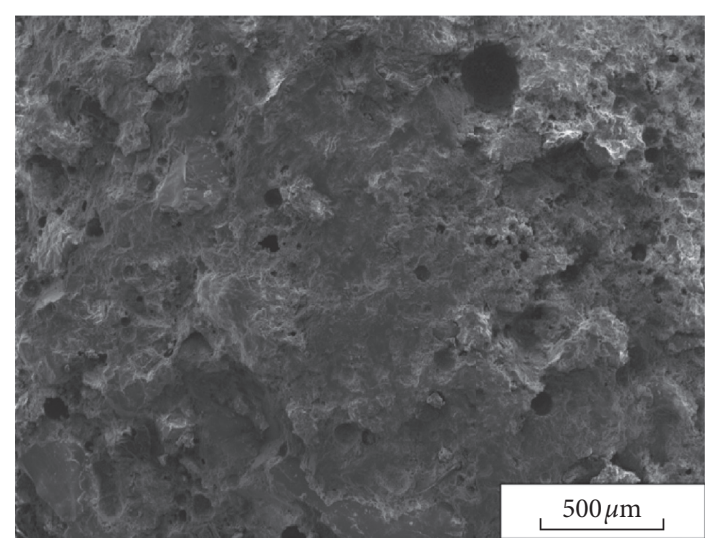

FIGURE 18: Surface morphology of reference concrete.

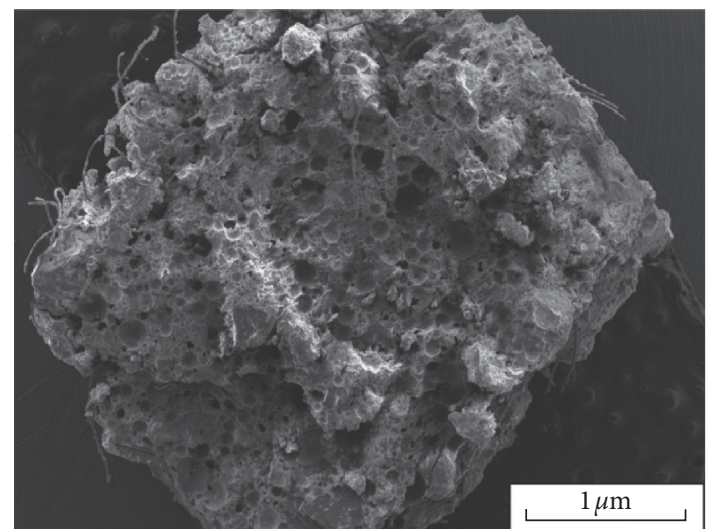

FIGURE 19: Surface topography of concrete mixed with rubber and fiber.

\section{Conclusions}

In the experiment, a kind of concrete mixed with the rubber powder and PVA fiber was prepared, and the static mechanics test and free vibration test of these specimens were carried out. The following conclusions were drawn from the current results:

(1) In the range of the test dosage, PVA fiber can improve the compressive strength at 28 days, but the compressive strength decreases with the increase of the rubber content. The fibers cannot compensate for the weakening effect of rubber on compressive strength. Moreover, both fiber and rubber reduce the flexural strength of concrete.

(2) The results of the free vibration test show that the damping ratio can be increased by various energy dissipation methods provided by the PVA fiber. Rubber also improved the damping ratio, but it would weaken with the increase of the rubber content. With the increase of the damage stage of the cantilever beam, the damping ratio first increased and then decreased, and its maximum value was about 3 times that of the nondamage stage. 
(3) The addition of fiber increases the dynamic stiffness of the cantilever beam, but the increase of the rubber powder will aggravate the loss of dynamic stiffness. By analyzing the relationship between displacement angle and damage index, it is found that the damage index of dynamic stiffness increases with the increase of displacement angle.

(4) The relative damping ratio of concrete increases with the reduction of mechanical strength. For fiber concrete, when the rubber content is $5 \%$, its damping ratio increases to the maximum, and its strength decreases within $30 \%$.

(5) Microscopic experiments show that the pores of rubber and its weak adhesion to the cement matrix and the bridging and blocking effects of the PVA fiber have positive effects on increasing the damping ratio, but they reduce the mechanical strength.

(6) According to the material content and concrete preparation method described in this experiment, the damping ratio of concrete prepared with a rubber content of $5 \%$ and fiber content of $2.4 \mathrm{~kg} / \mathrm{m}^{3}$ is increased to $3.83 \%$, and the compressive strength is 34.8 MPa.

As mentioned earlier, this study is expected to provide a mixture that enhances the damping ratio as a damping building material. Further research is needed in this field to address issues missing from the literature, such as the dispersion of fibers and rubber powder and application of composite concrete in structural members. Furthermore, the influence of PVA fiber length and thickness on damping ratio of composite concrete is still unclear and needs further study.

\section{Data Availability}

The data are not available for publication for the moment because they relate to other unpublished articles in the same research group.

\section{Disclosure}

The authors declare that the work described was original research that has not been published previously and not under consideration for publication elsewhere, in whole or in part.

\section{Conflicts of Interest}

The authors declare no conflicts of interest.

\section{Authors' Contributions}

Linling Ma, BinWang, Yunfeng Xiao, Heng Zhang, and Zhen Li investigated the study. Linling Ma contributed to data curation and wrote the original draft. Bin Wang reviewed and edited the article. Lei Zeng, Zhen Li, and Heng Zhang supervised the study. Lei Zeng and Yunfeng Xiao administered the project. Lei Zeng was responsible for funding acquisition. The manuscript was approved by all authors for publication.

\section{Acknowledgments}

The authors thank the National Natural Science Foundation of China (Grant no. 51978078) and the Natural Science Foundation of Hubei Province (Grant no. 2015CFA029) for supporting this study, and they would like to express their heartfelt thanks to the technical staff who helped them throughout the research process.

\section{References}

[1] I. G. Buckle and R. L. Mayes, "Seismic isolation: history, application, and performance-A world view," Earthquake Spectra, vol. 6, no. 2, pp. 161-201, 1990.

[2] X.-L. Rong, S.-S. Zheng, Y.-X. Zhang, X.-Y. Zhang, and L.-G. Dong, "Experimental study on the seismic behavior of RC shear walls after freeze-thaw damage," Engineering Structures, vol. 206, Article ID 110101, 2020.

[3] X. Xie, Z. Wang, D. Liu, G. Du, and J. Zhang, "An experimental study on a novel cylinder harvester made of L-shaped piezoelectric coupled beams with a high efficiency," Energy, vol. 212, Article ID 118752, 2020.

[4] X. Hu, Y. Li, and X. Xie, "A study on a U-shaped piezoelectric coupled beam and its corresponding ingenious harvester," Energy, vol. 185, pp. 938-950, 2019.

[5] S. Xiang, L. Zeng, Y. Liu et al., "Experimental study on the dynamic behavior of $\mathrm{T}$-shaped steel reinforced concrete columns under impact loading," Engineering Structures, vol. 208, Article ID 110307, 2020.

[6] C. C. Thong, D. C. L. Teo, and C. K. Ng, "Application of polyvinyl alcohol (PVA) in cement-based composite materials: a review of its engineering properties and microstructure behavior," Construction and Building Materials, vol. 107, no. Mar.15, pp. 172-180, 2016.

[7] Y. Ling, P. Zhang, J. Wang, and Y. Chen, "Effect of PVA fiber on mechanical properties of cementitious composite with and without nano-SiO2," Construction and Building Materials, vol. 229, Article ID 117068, 2019.

[8] A. Noushini, K. Vessalas, and B. Samali, "Static mechanical properties of polyvinyl alcohol fibre reinforced concrete (PVA-FRC)," Magazine of Concrete Research, vol. 66, no. 9, pp. 465-483, 2014.

[9] A. Passuello, G. Moriconi, and S. P. Shah, "Cracking behavior of concrete with shrinkage reducing admixtures and PVA fibers," Cement and Concrete Composites, vol. 31, no. 10, pp. 699-704, 2009.

[10] J. J. Shi, J. Ming, and M. Wu, "Electrochemical behavior and corrosion products of Cr-modified reinforcing steels in saturated $\mathrm{Ca}(\mathrm{OH})(2)$ solution with chlorides," Cement and Concrete Composites, vol. 110, p. 12, 2020.

[11] H. N. Atahan, B. Y. Pekmezci, and E. Y. Tuncel, "Behavior of PVA fiber-reinforced cementitious composites under static and impact flexural effects," Journal of Materials in Civil Engineering, vol. 25, no. 10, pp. 1438-1445, 2013.

[12] T. Susanto, A. Vahid, and C. P. Ostertag, "Flexural behavior and durability properties of high performance hybrid-fiber-reinforced concrete," Construction and Building Materials, vol. 182, pp. 504-515, 2018.

[13] S. Hamoush, T. Abu-Lebdeh, and T. Cummins, "Deflection behavior of concrete beams reinforced with PVA micro- 
fibers," Construction and Building Materials, vol. 24, no. 11, pp. 2285-2293, 2010.

[14] L. Zeng, Y. Xiao, J. Chen, and Y. Chen, "Quasi-static cyclic test on a concrete-encased frame-reinforced concrete tube building model," Shock and Vibration, vol. 2018, no. 6, pp. 1-14, 2018.

[15] X. Xie, J. Zhang, Z. Wang, and G. Song, "An experimental study on a high-efficient multifunctional U-shaped piezoelectric coupled beam," Energy Conversion and Management, vol. 224, Article ID 113330, 2020.

[16] J. G. Jang, H. K. Kim, T. S. Kim, B. J. Min, and H. K. Lee, "Improved flexural fatigue resistance of PVA fiber-reinforced concrete subjected to freezing and thawing cycles," Construction and Building Materials, vol. 59, pp. 129-135, 2014.

[17] M. Ahmaran, E. Zbay, and E. Hasan, "etc. Frost resistance and microstructure of Engineered Cementitious Composites: influence of fly ash and micro poly-vinyl-alcohol fiber," Cement and Concrete Composites, vol. 34, no. 2, pp. 156-165, 2012.

[18] Ş.. Mustafa, M. Lachemi, and V. C. Li, "Assessing the durability of engineered cementitious composites under freezing and thawing cycles," Journal of ASTM International, vol. 6, no. 7, 2009.

[19] P. Viswanath and E. T. Thachil, "Properties of polyvinyl alcohol cement pastes," Materials and Structures, vol. 41, no. 1, pp. 123-130, 2007.

[20] M. Said, A. A. Abd El-Azim, M. M. Ali, H. El-Ghazaly, and I. Shaaban, "Effect of elevated temperature on axially and eccentrically loaded columns containing Polyvinyl Alcohol (PVA) fibers," Engineering Structures, vol. 204, Article ID 110065, 2020.

[21] S. Pourfalah, "Behaviour of engineered cementitious composites and hybrid engineered cementitious composites at high temperatures," Construction and Building Materials, vol. 158, no. C, pp. 921-937, 2018.

[22] R.-D. Cao, H.-W. Yang, and G.-Y. Lu, "Effects of high temperature on the burst process of carbon fiber/PVA fiber high-strength concretes," Materials, vol. 12, no. 6, p. 973, 2019.

[23] Y. Liu, L. Zeng, S. Xiang et al., "Compressive performance evaluation of concrete confined by stirrups at elevated temperature using DIC technology," Construction and Building Materials, vol. 260, Article ID 119883, 2020.

[24] A. Noushini, B. Samali, K. Vessalas, and K. Vessalas, "Effect of polyvinyl alcohol (PVA) fibre on dynamic and material properties of fibre reinforced concrete," Construction and Building Materials, vol. 49, pp. 374-383, 2013.

[25] J. Mo, L. Zeng, Y. Liu et al., "Mechanical properties and damping capacity of polypropylene fiber reinforced concrete modified by rubber powder," Construction and Building Materials, vol. 242, Article ID 118111, 2020.

[26] O. Youssf, J. E. Mills, and R. Hassanli, "Assessment of the mechanical performance of crumb rubber concrete," Construction and Building Materials, vol. 125, pp. 175-183, 2016.

[27] K. Bisht and P. V. Ramana, "Evaluation of mechanical and durability properties of crumb rubber concrete," Construction and Building Materials, vol. 155, no. nov.30, pp. 811-817, 2017.

[28] F. Liu, W. Zheng, L. Li, W. Feng, and G. Ning, "Mechanical and fatigue performance of rubber concrete," Construction and Building Materials, vol. 47, no. Complete, pp. 711-719, 2013.

[29] M. Jalal, N. Nassir, and H. Jalal, "Waste tire rubber and pozzolans in concrete: a trade-off between cleaner production and mechanical properties in a greener concrete," Journal of Cleaner Production, vol. 238, Article ID 117882, 2019.
[30] W. Feng, F. Liu, F. Yang et al., "Experimental study on the effect of strain rates on the dynamic flexural properties of rubber concrete," Construction and Building Materials, vol. 224, pp. 408-419, 2019.

[31] L. Zeng, W. Ren, and Z. Zou, "etc. Experimental study on seismic behavior of frame structures composed of concrete encased columns with L-shaped steel section and steel beams," Earthquake Structure, vol. 16, no. 1, pp. 97-107, 2019.

[32] S. Dezhampanah, I. Nikbin, S. Charkhtab, F. Fakhimi, S. M. Bazkiaei, and R. Mohebbi, "Environmental performance and durability of concrete incorporating waste tire rubber and steel fiber subjected to acid attack," Journal of Cleaner Production, vol. 268, Article ID 122216, 2020.

[33] T. Li, J. Xiao, T. Sui, C. Liang, and L. Li, "Effect of recycled coarse aggregate to damping variation of concrete," Construction and Building Materials, vol. 178, pp. 445-452, 2018.

[34] S. Mei, L. Su, and P. Li, "Etc. Material damping of concrete under cyclic axial compression," Journal of Materials in Civil Engineering, vol. 30, no. 3, 2018.

[35] J. Xue and M. Shinozuka, "Rubberized concrete: a green structural material with enhanced energy-dissipation capability," Construction and Building Materials, vol. 42, no. may, pp. 196-204, 2013.

[36] B. S. Thomas and R. Chandra Gupta, "Properties of high strength concrete containing scrap tire rubber," Journal of Cleaner Production, vol. 113, pp. 86-92, 2016.

[37] M. M. Al-Tayeb, B. H. Abu Bakar, H. Ismail, and H. M. Akil, "Effect of partial replacement of sand by recycled fine crumb rubber on the performance of hybrid rubberized-normal concrete under impact load: experiment and simulation," Journal of Cleaner Production, vol. 59, pp. 284-289, 2013.

[38] C. Liang, T. Liu, J. Xiao, D. Zou, and Q. Yang, "The damping property of recycled aggregate concrete," Construction and Building Materials, vol. 102, no. JAN.15.1, pp. 834-842, 2016.

[39] M. Ali, A. Liu, H. Sou, and N. Chouw, "Mechanical and dynamic properties of coconut fibre reinforced concrete," Construction and Building Materials, vol. 30, pp. 814-825, 2012.

[40] B. S. Thomas, R. C. Gupta, P. Kalla, and L. Cseteneyi, "Strength, abrasion and permeation characteristics of cement concrete containing discarded rubber fine aggregates," Construction and Building Materials, vol. 59, pp. 204-212, 2014.

[41] F. Valadares, M. Bravo, and J. de Brito, "Concrete with used tire rubber aggregates: mechanical performance," ACI Mater. J. Am. Concr. Institute, vol. 109, p. 283, 2012.

[42] I. B. Topçu, "The properties of rubberized concretes," Cement and Concrete Research, vol. 25, no. 2, pp. 304-310, 1995.

[43] A. M. Ghaly and J. D. Cahill IV, "Correlation of strength, rubber content, and water to cement ratio in rubberized concrete," Canadian Journal of Civil Engineering, vol. 32, no. 6, pp. 1075-1081, 2005.

[44] R. W. Clough and J. Penzien, Dynamics of structures, Computers and Structures, New York, NY, USA, 2003.

[45] Y. J. Park and A. H. S. Ang, "Mechanistic seismic damage model for reinforced concrete," Journal of Structural Engineering, vol. 111, no. 4, pp. 722-739, 1985. 